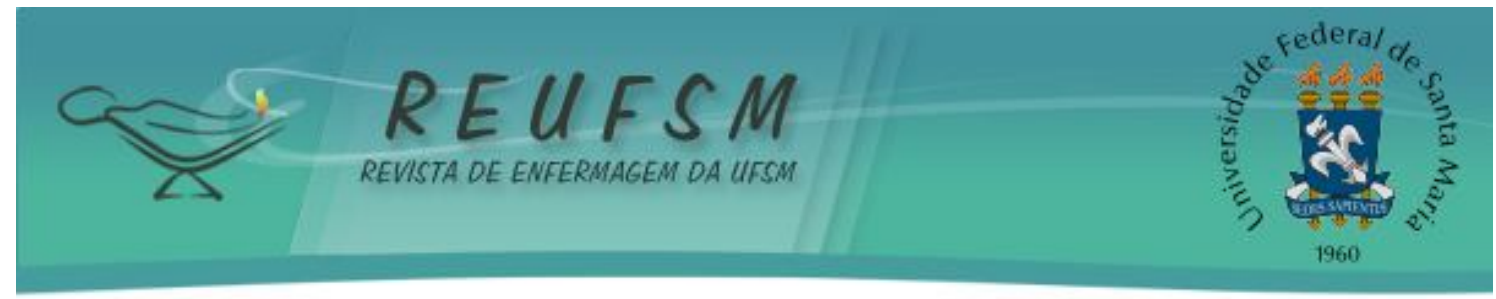

ARTIGO ORIGINAL

\title{
CORONARIOGRAFIA NO LABORATÓRIO DE HEMODINÂMICA EM UM HOSPITAL PÚBLICO: CONHECIMENTO DOS PACIENTES
}

\section{CORONARIOGRAPHY IN THE HEMODY NAMIC LABORATORY IN A PUBLIC HOSPIT AL: KNOWLEDGE OF THE PATIENTS \\ CORONARIOGRAFÍA EN EL LABORATORIO DE HEMODINÁMICA EN UN HOSPITAL PÚBLICO:CONOCIMIENTO DE LOS PACIENTES}

\author{
Christian Menuci ${ }^{1}$ \\ Mara Ambrosina de Oliveira Vargas ${ }^{2}$
}

\begin{abstract}
RESUMO: Investigação qualitativa exploratória com o objetivo de identificar o conhecimento dos pacientes que se submetem a coronariografia no Laboratório de Hemodinâmica de um Hospital Público. Após aprovação do Comitê de Ética e Pesquisa, efetivou-se a coleta de dados por entrevista semi-estruturada com os pacientes maiores de 18 anos, portadores de cardiopatias encaminhados pela primeira vez para realização eletiva de coronariografia. 0 número de participantes totalizou 15 (quinze), determinado por saturação dos dados. Na Análise Temática, foram explorados os temas desconhecimento dos pacientes sobre o exame coronariografia e importância da orientação prévia no conhecimento dos pacientes. Concluiu-se que os profissionais de enfermagem necessitam revigorar a sua capacidade de comunicação com os pacientes. Pode-se corroborar que a orientação adequada minimizaria o desconhecimento dos pacientes acerca do exame coronariografia. Há necessidade de estudos que validem modos de efetivar orientações articulados à diminuição da ansiedade e insegurança do paciente e das complicações do procedimento.
\end{abstract}

Descritores: Enfermagem; Educação em enfermagem; Conhecimento; Angiografia coronária; Cardiologia.

ABSTRACT: It is a qualitative and exploratory research aimed at identifying the knowledge of patients who undergo coronariography in the Hemodynamic Laboratory of a Public Hospital. After approval by the Ethics and Research Committee, the data collection was carried out by means of semi-structured interview applied to patients of age above 18 years old with heart disease with indication for elective coronariography for the first time. The total number of participants reached 15 (fifteen), as determined by data saturation. The Thematic Analysis explored the following themes: patients' lack of knowledge about the coronariography exam and the importance of a previous orientation to patients. The conclusion drawn is that nursing professionals need to improve their capacity of communication with the patients. One can corroborate that an adequate orientation would minimize the patients' lack of knowledge regarding the coronariography exam. Studies are needed to validate ways to verify orientations articulated with the patients' reduction of anxiety and uncertainty about the procedure complications.

Descriptors: Nursing; Nursing education; Knowledge; Coronary angiography; Cardiology.

\footnotetext{
${ }^{1}$ Enfermeiro. Graduação em Enfermagem pela Universidade do Vale do Rio dos Sinos (UNISINOS). Atua no Serviço de Hemodinâmica do Hospital Mãe de Deus e do Hospital Nossa Senhora da Conceição. E-mail: christian.menuci@gmail.com

${ }^{2}$ Enfermeira. Doutora em Enfermagem pela Universidade Federal de Santa Catarina (UFSC). Professor Titular UNISINOS. Membro do Grupo Práxis na UFSC. Coordenadora da Especialização em Enfermagem em Terapia Intensiva na UNISINOS e Universidade Corporativa Hospital Mãe de Deus. E-mail: maraav@terra.com.br
} 


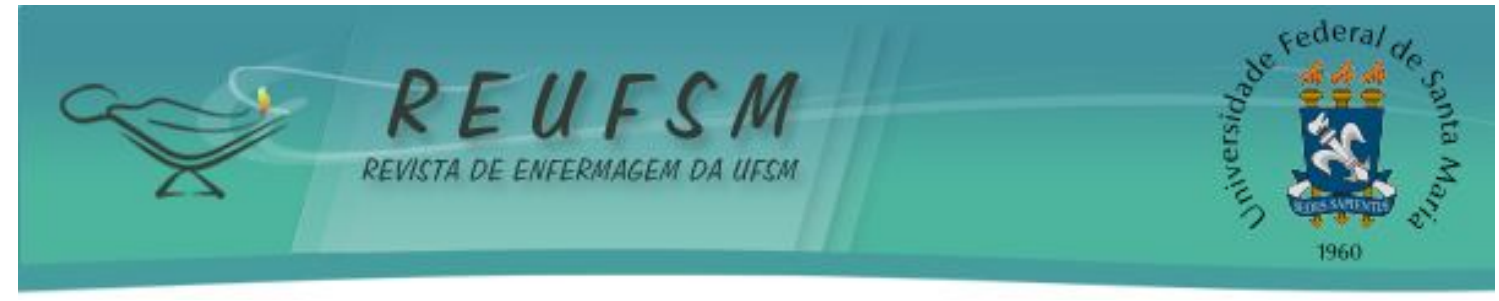

RESUMEN: Investigación cualitativa y exploratoria con el objetivo de identificar el conocimiento de los pacientes que se someten a coronariografía en el Laboratorio de Hemodinámica de un hospital público. Tras la aprobación del Comité de Ética e Investigación, se realizó la recolección de datos por medio de una entrevista semiestructurada con pacientes de más de 18 años de edad, portadores de cardiopatías, conducidos por primera vez a la realización electiva de coronariografía. El número de participantes totalizó 15 (quince), determinado por la saturación de los datos. A través del Análisis Temático, se exploraron los temas desconocimiento de los pacientes acerca del examen coronariografía e importancia de la orientación previa en el conocimiento de los pacientes. Se concluyó que los profesionales de enfermería necesitan renovar su capacidad de comunicación con los pacientes. Se puede corroborar que la orientación adecuada minimizaría el desconocimiento de los pacientes acerca del examen coronariografía. Hay necesidad de estudios que validen modos de hacer efectivas las orientaciones dirigidas a la disminución de la ansiedad e inseguridad del paciente y de las complicaciones del procedimiento.

Descriptores: Enfermería; Educación en enfermaría; Conocimiento; Angiografía coronaria; Cardiología.

\section{INTRODUÇÃO}

0 aumento gradativo de pessoas com cardiopatias isquêmicas no Brasil e no mundo faz com que os Laboratórios de Hemodinâmica tenham cada vez mais pacientes encaminhados para a realização de coronariografia. A cinecoronariografia consiste na filmagem de imagens obtidas com a injeção de contraste radiológico através de sondas colocadas nas artérias coronárias. Este exame começou a ser realizado em 1945 com Radmer, ao visualizar as artérias coronárias por injeção não-seletiva de contraste na aorta ascendente, porém, foi introduzido como método diagnóstico em 1962 por Mason Sones J r. ${ }^{1}$

0 cateterismo cardíaco esquerdo é a introdução de um cateter retrógrado por via arterial, por meio de punção percutânea da artéria femoral, braquial e radial ou dissecção da artéria braquial. Esse cateter é introduzido até a raiz da aorta através de radioscopia; nesse local, com movimentos de vai-e-vem e rotação da porção externa, dirige-se a ponta do cateter até penetrar nos óstios da artéria coronária direita e esquerda. Por meio de injeção de contraste, as artérias coronárias são filmadas em diversas projeções radiológicas para visualização correta da localização, comprimento, diâmetro e contorno das coronárias, da presença e severidade das lesões, de características e natureza das obstruções (incluindo a presença de ateromas, trombos, dissecção, espasmo ou ponte miocárdica) e análise do fluxo coronariano. Logo, este exame é parte de uma avaliação diagnóstica invasiva completa da condição cardiovascular do paciente, do surgimento e da progressão da aterosclerose coronariana. ${ }^{2}$

O cateterismo cardíaco diagnóstico é apropriado em várias circunstâncias. Em primeiro, é indicado para confirmar ou excluir a presença de uma condição já suspeita por exame físico ou avaliação não-invasiva. Nessa circunstância, ele permite tanto estabelecer a presença de cardiopatia quanto avaliar sua gravidade. Em segundo, está preconizado para elucidar um quadro clínico duvidoso em um paciente cujos achados clínicos e os dados não-invasivos não forem conclusivos. Em terceiro, o cateterismo é realizado em alguns pacientes com indicação de cirurgia cardíaca corretiva para confirmar uma anormalidade suspeita e para excluir uma anormalidade associada que poderia demandar a atenção do cirurgião. Quarto, a coronariografia, ocasionalmente, é realizada puramente como um procedimento de pesquisa. $^{3}$ 


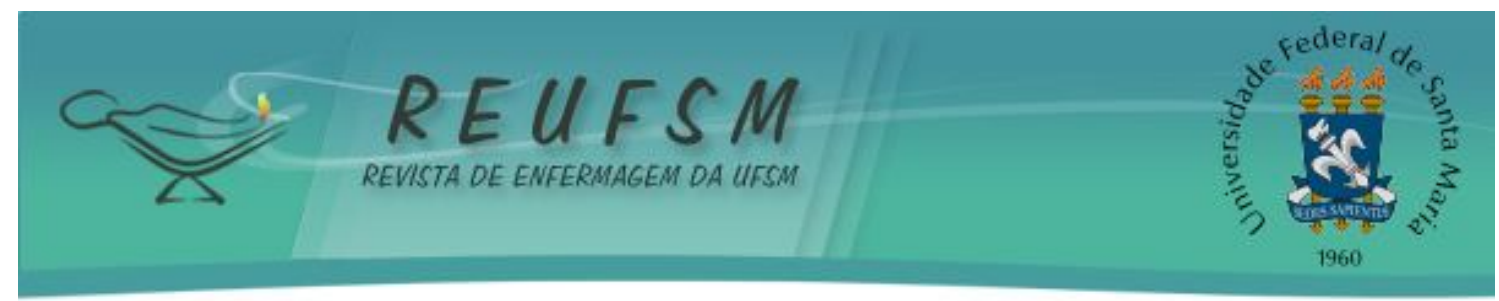

Atender um paciente que irá realizar o cateterismo cardíaco exige dos cuidadores de saúde (entre estes o enfermeiro e os técnicos de enfermagem) um conjunto de conhecimentos, habilidades e atitudes que podem repercutir: na qualidade das intervenções usuais durante e após o procedimento; na orientação quanto ao preparo adequado do paciente para a realização do exame; na cooperação do paciente durante 0 exame; na diminuição da ansiedade e insegurança do paciente e na detecção imediata das intercorrências que podem surgir durante e após o procedimento. Portanto, o elemento diferenciador nesse atendimento será a capacidade de dedicação que tem a equipe multiprofissional do laboratório de hemodinâmica no cuidado a esses pacientes. ${ }^{2}$

Neste ínterim, a comunicação é um aspecto que precisa ser agregada e potencializada pela enfermagem. Ela está presente no seu dia a dia, em todas as ações realizadas com o paciente, seja para orientar, informar, apoiar, confortar ou atender às suas necessidades básicas. ${ }^{4}$ Especificadamente, a orientação é uma forma de esclarecer as dúvidas que a intervenção provoca. $E$, o enfermeiro e a sua equipe são os profissionais que, além de instrumentalizados para realizá-la, são responsabilizados legal e moralmente a fazê-la, preparando o paciente para o procedimento a ser realizado e informando-Ihes sobre os riscos e benefícios, em linguagem acessível. ${ }^{5}$

Mas, a orientação deveria ser implementada e, posteriormente, monitorizada para avaliação do impacto da mesma no conhecimento dos usuários de saúde acerca do seu processo saúde-doença. Nesta direção, interessa, aqui, saber se a equipe de saúde (entre estes o enfermeiro e a equipe de enfermagem) prioriza e efetiva uma orientação capaz de promover o conhecimento dos pacientes acerca das intervenções e dos cuidados aos quais se submetem no exame de coronariografia no Laboratório de Hemodinâmica? Para tanto, efetuado este estudo em uma instituição hospitalar que entre 2008 e 2009, foram realizadas 1.204 coronariografias, tanto eletivas quanto de urgência, perfazendo uma média de 602 procedimentos anuais. Assim, constituído como objetivo: identificar 0

conhecimento dos pacientes que se submetem à coronariografia no Laboratório de Hemodinâmica de um hospital público de Porto Alegre sobre o exame realizado.

\section{MÉTODO}

Estudo do tipo exploratório com abordagem qualitativa, efetivado no Laboratório de Hemodinâmica do Hospital Nossa Senhora da Conceição, localizado na cidade de Porto Alegre. Esta instituição hospitalar é considerada uma referência no Rio Grande do Sul (RS), disponibilizando assistência integral à saúde da população, além de estar engajada em ações de ensino e pesquisa. A instituição dispõe de 840 leitos e possui a maior Emergência do RS, atendendo diariamente cerca de 800 pessoas. No Laboratório de Hemodinâmica deste hospital, são realizados exames de pacientes já internados e exames de pacientes de ambulatório, de segunda a sexta-feira, das sete às dezenove horas, disponibilizando à população a realização de arteriografia cerebral, arteriografia de carótidas e de membros superiores, coronariografia, cateterismo cardíaco direito, aortografia torácica e abdominal, arteriografia de vasos abdominais e de membros inferiores. Além disso, abrange a parte intervencionista cardíaca, como angioplastias eletivas e de urgências, valvuloplastias e embolizações; conta também com uma equipe habilitada para inserção de endopróteses. Os pacientes submetidos a exames na Hemodinâmica são encaminhados à sala de recuperação, se necessário, e os demais permanecem na sala de exame o tempo necessário para a compressão manual da artéria puncionada e após fazem o período de repouso em seus leitos na unidade de internação ou unidade de terapia intensiva. A equipe profissional é composta por quatro técnicos em enfermagem, três técnicos de radiologia, 


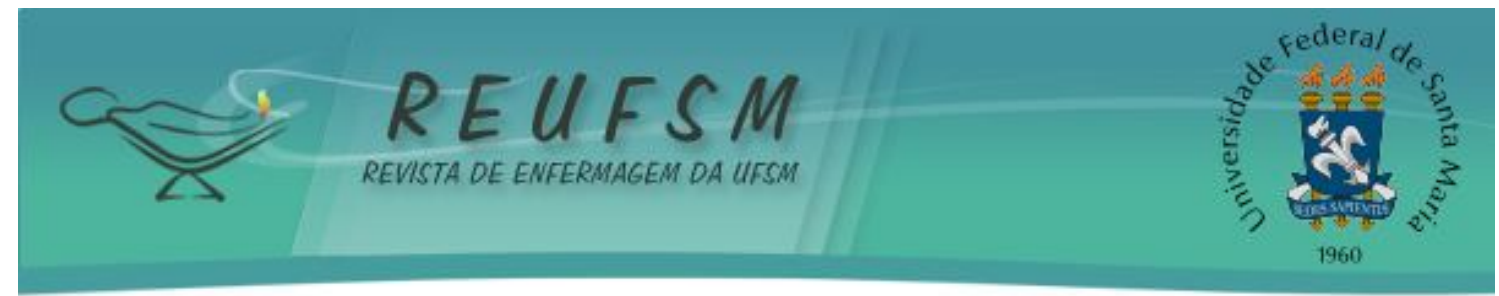

duas enfermeiras, uma secretária, um estagiário na secretaria, quatro médicos cardiologistas-intervencionistas, um médico vascular e duas pessoas na higienização.

Os sujeitos de pesquisa compreenderam os pacientes portadores de cardiopatias encaminhados ao Laboratório de Hemodinâmica para a realização eletiva da coronariografia. Os critérios de inclusão abrangiam: idade superior a 18 anos; encaminhamento para estudo hemodinâmico pela primeira vez; internação na instituição. O número de participantes totalizou 15 (quinze), determinado por saturação dos dados.

0 projeto foi aprovado em Comitê de Ética (Parecer $n^{\circ}$ 10-051/2010/CEP/GHC), e os sujeitos manifestaram seu aceite por meio do Termo de Consentimento Livre e Esclarecido, conforme Resolução 196/96. A coleta das informações foi realizada nos meses de junho e julho de 2010, mediante entrevista individual, semiestruturada, gravada em fita cassete, efetivada logo após o término do procedimento, antes da retirada do introdutor arterial, no turno da manhã. O formulário da entrevista continha dados sociodemográficos e comorbidades para caracterização dos sujeitos do estudo, além de quatro perguntas: 1) Houve algum tipo de desconforto ou dificuldade antes, durante ou após a realização do seu exame? Qual? 2) 0 que o(a) senhor(a) conhecia ou conhece do exame que realizou? 3) Quais orientações você recebeu da equipe de saúde antes do exame? $O(A)$ senhor(a) acha que estas orientações foram suficientes? Por quê? 4) $O(A)$ senhor(a) acha que seria bom receber orientações por escrito sobre o exame? A análise das informações segue o modelo de Análise Temática, conforme Minayo. ${ }^{6}$

\section{ANÁLISE E DISCUSSÃO DOS RESULTADOS}

Os resultados das entrevistas possibilitaram a análise dos temas "desconhecimento dos pacientes acerca do exame coronariografia" e "importância da orientação prévia no conhecimento dos pacientes".

\section{Desconhecimento dos pacientes sobre o exame coronariografia}

0 paciente encaminhado ao laboratório de hemodinâmica para a realização da coronariografia precisa conhecer aspectos pertinentes ao procedimento. Para tanto, os profissionais de saúde devem explicitar previamente ao exame: a necessidade dos exames pré-operatórios (tipagem sanguínea, exames laboratoriais de sangue); a via de acesso para a realização do procedimento (femoral, braquial ou transradial); os riscos de complicações; a retirada do introdutor; a necessidade do repouso após o procedimento e os cuidados durante e após exame. ${ }^{2}$

Muitos dos pacientes encaminhados para a realização deste procedimento específico nunca haviam entrado em um ambiente hospitalar e não sabiam da existência de seu problema de saúde. Agora, percebem-se deitados em uma mesa de exame, em uma situação de exposição, rodeados de vários aparelhos e de pessoas e com muitas interrogações, por exemplo: o que vocês vão fazer comigo? Que exame é esse? Dói muito? Eu vou dormir?

0 ambiente hospitalar, independentemente do local em que o paciente se encontra internado, é desconhecido, altera os hábitos e a autonomia dos indivíduos, tornando-os dependentes dos profissionais para atividades da vida diária. Essa sensação de dependência faz com que busquem na equipe de saúde não apenas a cura, mas segurança. ${ }^{7}$ Desconhecer, aqui, assume uma dimensão amplificada, pois, além do contexto hospitalar, os sujeitos desconheciam a própria intervenção à qual seriam submetidos. Nessa direção, sobre a pergunta "o que o(a) senhor(a) conhecia ou conhece do exame ao qual foi submetido(a)?", os informantes discorrem: 


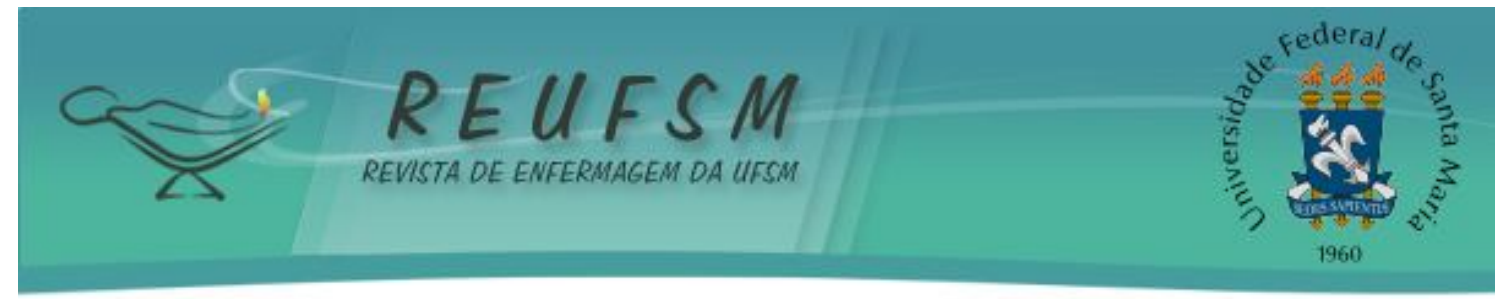

Nada. Nem sei que exame é esse que eu fiz!!! Para que serve mesmo? (II1).

Uma vez eu vi na novela um ator ir fazer um cateterismo, mas não entendi por que ele foi fazer (I7).

Todos os informantes do estudo estavam cientes de que não deveriam se alimentar durante um período estabelecido. Logo, ocorreu um contato do profissional da saúde com o paciente para que a orientação do jejum fosse priorizada. No entanto, outras orientações pertinentes não ocorreram ou talvez tenham sido oferecidas de modo inadequado. Por exemplo, a maioria dos informantes ignorava que, durante o procedimento, a equipe poderia solicitar que tossisse ou prendesse e soltasse a respiração, virasse o rosto para a direita e para esquerda e se mantivesse imóvel na mesa de exame.

Ainda que não estivessem cientes das necessárias solicitações durante 0 procedimento, alguns pacientes verbalizaram ter uma pequena noção prévia do que era a coronariografia:

Tinha uma pequena ideia de como era o exame, mas só me lembro do que as outras pacientes falavam no quarto, que era bem perigoso, que colocavam um caninho na virilha. (I6)

Só o que meu vizinho de quarto me falou, que ia dar uma injeção na virilha e que tinha um cateter que iria até o coração com uma câmera na ponta. (19)

Que comportamento esperar de um paciente que nunca se internou em um hospital, nada ciente de sua doença cardíaca e sem orientação prévia sobre o que iria acontecer? Espera-se, sempre, que quanto maior o entendimento das orientações passadas ao paciente, menor será a sua ansiedade e medo em relação à intervenção. Mas, para se obter um melhor resultado na orientação, é importante, tanto conhecer as expectativas do paciente, como avaliar a sua capacidade de entender as informações fornecidas. ${ }^{7}$

0 período de repouso no leito após cateterismo cardíaco tem sido objeto de investigações ${ }^{(8 ; 9)}$ nos últimos anos, buscando um possível consenso a respeito do tempo ideal de repouso após a retirada da bainha femoral. No Brasil, recente estudo clínico randomizado ${ }^{10}$, ao avaliar a segurança na redução do tempo de repouso no leito, de seis para três horas, após cateterismo cardíaco diagnóstico com introdutor $6 \mathrm{~F}$, concluiu que a redução do tempo de repouso para três horas é segura. ${ }^{10} \mathrm{~A}$ rotina da instituição onde 0 estudo foi realizado indica o repouso de seis horas do membro puncionado quando o exame é realizado pela via femoral. Este é outro fator apontado pelos informantes como gerador de dúvidas:

Ouvi falar que, depois do exame, a gente tem que ficar um dia inteiro sem se mexer, para a veia colar direitinho. É verdade? (I8)

Depois do exame, a gente pode caminhar um pouco? Não aguento mais ficar na maca. (I10)

Aguardar exames ou cirurgias pode fazer com que os pacientes, além de terem alto nível de estresse, desenvolvam sentimentos ${ }^{5}$ de insegurança, de tristeza e de medo da morte. Todos pacientes que se submetem ao cateterismo cardíaco assinam o Termo de Consentimento Livre e Esclarecido (TCLE) padronizado pela unidade de Hemodinâmica, no qual é relacionada uma série de eventos adversos que o exame pode oferecer ao paciente. 


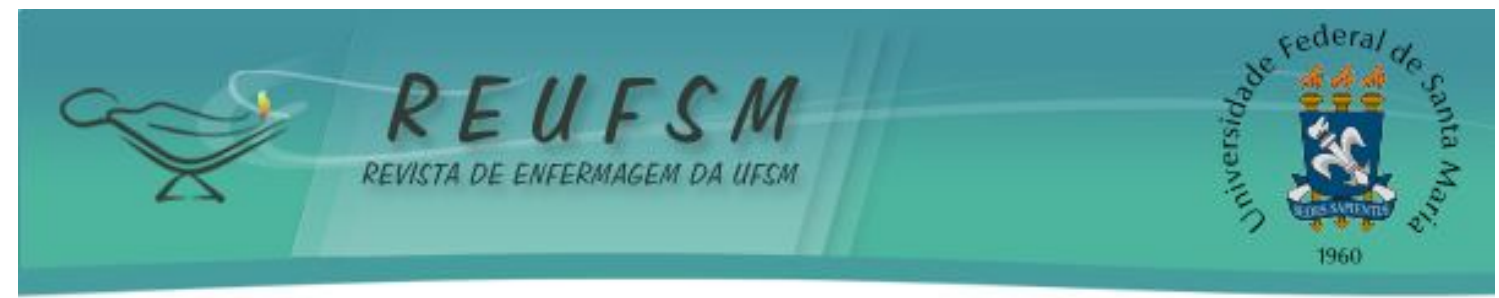

Será que esses pacientes leem o que assinam? Será que eles sanam suas dúvidas com a equipe de saúde sobre o que pode ocorrer durante o exame? A equipe explica o que significa os termos listados no Termo (danos vasculares, perda sanguínea, arritmia, infarto do miocárdio, infecções, perfuração cardíaca, isquemia miocárdica, choque anafilático, acidente cérebro-vascular, morte)? Em uma conversa com um dos entrevistados, quando o pesquisador entregava o TCLE da presente pesquisa, ele referiu uma frase sobre o TCLE do exame ao qual se submeteu:

Aquele outro papel onde diz o que posso ter de ruim no exame é igual a bula de remédio, se eu ler, eu vou ter, então assinei, mas não li, sei que é errado, mas é melhor não saber. (I10)

Para que um TCLE seja considerado um documento com validade legal, deve, entre outras, obedecer a algumas condições, como fornecimento de informações e compreensão por parte do paciente. ${ }^{11}$ Não foi objetivo do presente estudo verificar a leitura do TCLE pelo paciente, mas o referido termo é um dos meios para que o paciente tenha um pouco de conhecimento sobre o exame ao qual será submetido. No sétimo parágrafo do termo que a equipe fornece ao paciente, está descrito: "declaro ter-me sido explicado o significado dos termos técnicos usados nesse documento". Aí, é estabelecido claramente que os profissionais que atendem o paciente não devem apenas solicitar uma assinatura, e sim explicar detalhadamente, em linguagem acessível, devendo evitar termos complexos e palavras que o paciente não sabe o que significa, ajudando-o no processo de elucidar o exame. No entanto, fica o paradoxo: será que explicitar melhor os riscos e consequências do exame aumenta ou diminui a ansiedade, o medo e a apreensão que precede o exame? Conhecer o quê? $\operatorname{Estudiosos}^{(12 ; 13)}$ sinalizam que esse período de espera é um momento em que o paciente está preocupado com o que pode lhe acontecer durante o procedimento, levando-o a esquecer algumas das possíveis orientações que the são transmitidas.

\section{Importância da orientação prévia no conhecimento dos pacientes}

No hospital em estudo, não há rotina institucionalizada de orientação para exames de imagem, sendo ela realizada conforme aprendido com os profissionais mais antigos ou aplicando-se os conhecimentos adquiridos na formação profissional. Às perguntas quais orientações você recebeu da equipe de saúde antes do exame? e o(a) senhor (a) acha que estas orientações foram suficientes? Por quê? os informantes reforçaram:

Não recebi orientação, ninguém falou comigo. Acho que seria bom que alguém tivesse falado comigo, pelo menos para que era 0 exame, daí não ficaria tão nervosa. (I12)

Conversaram com a minha esposa, e ela disse que não entendeu muita coisa. (I1)

Estou muito nervoso [choro], nada explicaram, nem para que eu precisava depilar a virilha. (I6)

Só me deram um papel para assinar, e que o exame era pela virilha. Não foram suficientes, porque eu não sabia nada do exame e continuo sem saber. (I3)

O processo de trabalho da maioria dos laboratórios de hemodinâmica dificulta o contato prévio do enfermeiro e sua equipe de enfermagem com 0 


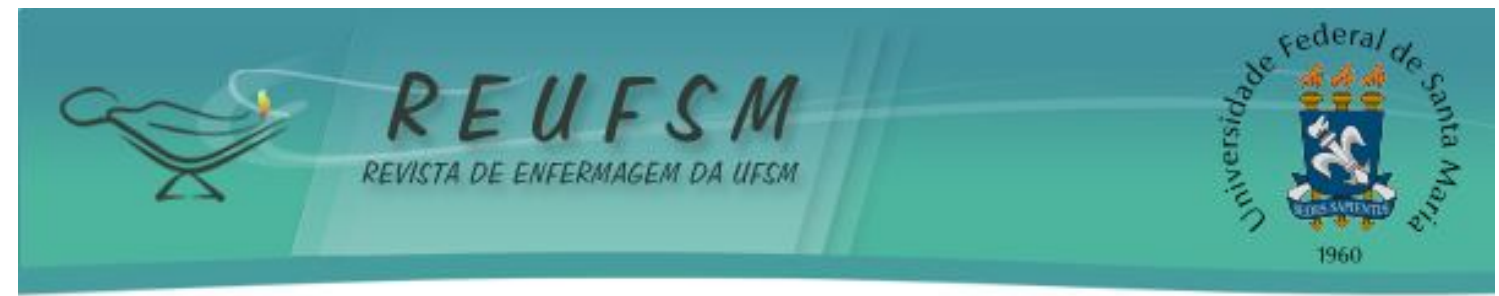

paciente e seus familiares, sendo que, em muitos serviços, a equipe nem chega a conhecê-los previamente. Devido ao tempo relativamente curto de intervenção, em média vinte minutos, somente alguns dados relevantes à execução do exame são coletados pelo técnico de enfermagem, tais como: sinais vitais, peso e altura e alergia a iodo. ${ }^{13}$ Os sujeitos da pesquisa reclamaram da falta de uma orientação prévia acerca do exame:

Seria muito bom se alguém tivesse conversado comigo sobre o exame, o meu vizinho de quarto até me explicou, mas não entendi muito bem. (I12)

Não tinham me falado nada sobre o exame. Será que era mesmo necessário fazer? [...] estava com medo de morrer, ainda estou muito nervoso! (I15)

Como a orientação prévia não é priorizada, a equipe de enfermagem e médica do laboratório de hemodinâmica, procura minimizar esta problemática enquanto prepara 0 paciente para o procedimento, explicando-Ihe como ele deve se comportar durante 0 exame, por onde é realizada a punção e o porquê da solicitação da coronariografia. Muitas vezes, a equipe conforta o paciente para diminuir a ansiedade, provocada pelo desconhecimento do procedimento.

Orientar e informar por meio de um diálogo compreensível favorece o bemestar do paciente. ${ }^{14}$ É factível que clientes agendados para qualquer exame diagnóstico invasivo apresentam as mesmas inquietações: ansiedade relacionada à ameaça à integridade física e ao bem-estar, como também quanto às implicações advindas do resultado diagnóstico. ${ }^{13}$

A ansiedade é caracterizada por um conjunto de manifestações físicas, tais como: taquicardia, sudorese, hiperventilação, tensão muscular e psicológica, evidenciadas por apreensão, alerta e inquietude. Logo, pode-se supor que o seu controle durante a realização da coronariografia é de grande importância, pois o cliente menos ansioso colabora, mantendo-se em um posicionamento adequado na mesa de exames, apresentando menos reações indesejáveis e mantendo sinais vitais dentro de parâmetros seguros. ${ }^{13}$ Portanto, as manifestações físicas da ansiedade descritas podem ter potencial efeito deletério ao paciente que se submete ao cateterismo cardíaco, o que justifica a pertinência da realização de estudos que utilizem instrumentos validados para medir se a orientação diminui ou não a ansiedade dos pacientes.

Os pacientes também receberam orientações que não foram bem compreendidas por eles. Isto costuma acontecer por déficit na comunicação paciente-profissional, pela fragilidade emocional do paciente ou pela transmissão das informações em uma linguagem técnica, inacessível ao paciente:

Até me falaram umas coisas, mas não entendia nada que o doutor falava. Ele falava muito rápido. Não sei se foram suficientes [...] essas palavras difíceis que vocês falam (I14).

Falaram que era feito um cortezinho na perna para o cateter entrar no coração e que não podia me mexer durante o exame. Tinha umas coisas que a moça falou, mas não entendi (III).

Como dito acima, os profissionais de saúde orientaram, mas de modo rápido e difícil. Há profissionais que se esforçam para tranquilizar o seu cliente frente a alguma ansiedade iminente, porém, por desconhecimento do melhor manejo ou por onipotência, 


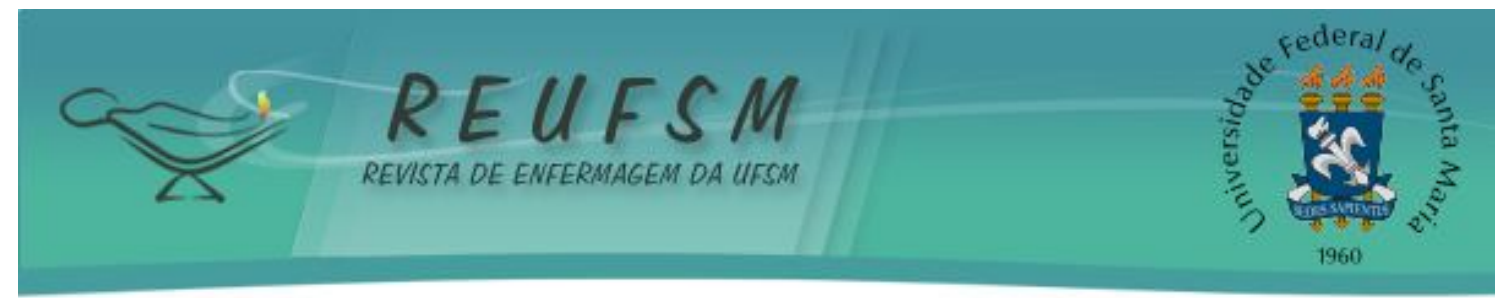

utilizam meios que deixam o paciente mais ansioso ainda, usando termos técnicos ou jargões. ${ }^{12}$ Ainda, perpassa na fala dos sujeitos acima, a noção de que os pacientes desistem de buscar uma orientação mais adequada. Pode-se inferir que quando o cuidado é realizado de modo automatizado, pode acontecer de o paciente achar que os profissionais de saúde se aborrecem facilmente com ele. Então, para não incomodá-los com mais perguntas, muitas vezes o paciente se cala.

Nesse sentido, a equipe de saúde, ao orientar sobre um exame, também tem que atentar para os gestos e expressões detectadas no paciente quando este diz que entendeu todas as orientações. É isso mesmo que ele transmite à equipe através da comunicação não-verbal? Uma mensagem recebida pelo paciente e não compreendida por ele pode provocar aumento da ansiedade e de suas preocupações. ${ }^{2}$ Portanto, o profissional tem que indagar: Por favor, poderia repetir o que acabei de Ihe informar?

Tanto os pacientes que não foram orientados, quanto os pacientes que receberam pouca ou inadequada orientação, expressaram-se por meio de várias perguntas, como se verifica nestas falas:

Para onde eu vou agora? Quantas horas tenho que ficar sem caminhar? (I11)

Quanto tempo eu tenho que ficar sem comer? Alguém fala comigo sobre o resultado do exame? (I10)

Isso que vocês fizeram é a cirurgia do coração? Agora eu não vou ter mais dor no peito? (I3)

Uma das indagações da pesquisa incitava os pacientes a considerar pertinente ou não a opção de receberem orientação por escrito, sobre o exame. Todos responderam positivamente, fato que sinaliza a possível necessidade da elaboração de um manual de orientação para os pacientes encaminhados ao Laboratório de Hemodinâmica:

Os meus familiares poderiam ler também e me explicar o que eu não entendesse. (I5)

Sim, seria bom, porque eu não ficaria tão nervoso, podendo ler 0 papel quantas vezes eu quisesse. (I8)

Sim. Ainda mais se tivesse um desenho mostrando por onde seria feito o exame, bem direitinho para nós entendermos. (I10)

Muitas vezes, apenas a orientação verbal não é suficiente devido ao fato de o paciente não compreendê-la, esquecê-la ou rejeitá-la. Em função disso, o fornecimento de orientações escritas pode se tornar um instrumento qualificado de apoio, e não de substituição, às orientações verbais.

Ao reforçar a questão da orientação escrita, sinaliza-se que um manual de orientação contendo informações de fácil entendimento pode promover o conhecimento e a satisfação do paciente, facilitar-Ihe a autonomia e promover sua adesão. É, portanto, uma forma de promover saúde. Contudo, os autores dos manuais necessitam pressupor que, para as mensagens relacionadas com a saúde serem eficazmente comunicativas, elas devem ser planejadas, precisas, relevantes e entendidas. 0 material escrito é um instrumento que facilita o processo educativo, uma vez que permite ao leitor uma leitura posterior, possibilitando-Ihe a superação de eventuais dificuldades através do processo de decodificação e de rememorização. ${ }^{15}$

\section{CONCLUSÃO}




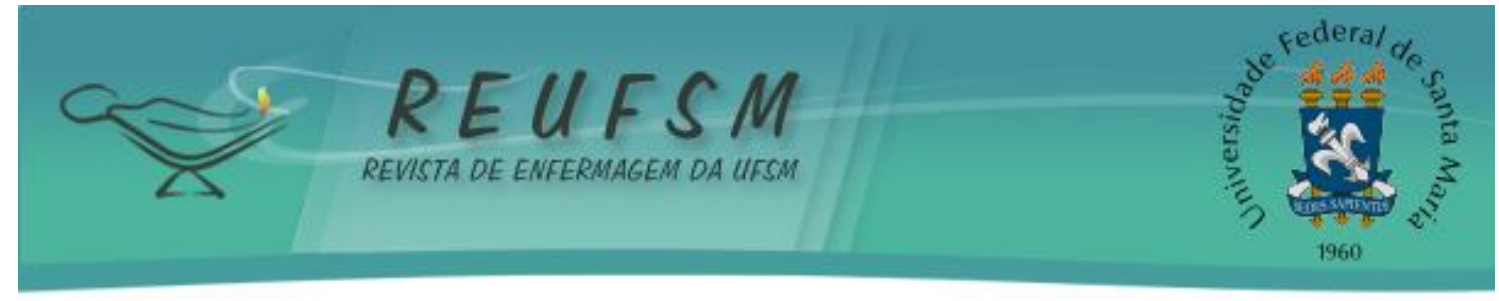

Desconhecer, nesta investigação, assume uma dimensão amplificada. Isto pode ser atribuído tanto à situação do paciente deparar-se com um diagnóstico inesperado como à complexidade da intervenção coronariografia. E, os dados demonstram a fragilidade da comunicação dos profissionais de saúde com os pacientes encaminhados para a realização da coronariografia.

Nas falas dos sujeitos da pesquisa, detectados desconhecimentos acerca: da necessidade e do tipo de anestesia durante o exame, da finalidade e do modo que o exame seria realizado, do tempo de duração do exame, da necessidade e do tempo de repouso após o término, dos encaminhamentos após o exame, da presença de dor e de qual seria o manejo para isto. No entanto, acredita-se que a ocorrência de uma orientação mais adequada, talvez suscite no paciente, outras indagações relativas ao procedimento.

Os dados encontrados neste estudo são relevantes para a área de conhecimento de enfermagem em cardiologia na medida em que evidencia questões importantes, as quais devem ser problematizadas pelos profissionais que atuam na enfermagem, almejando qualificar o cuidado. A proposta do estudo não contempla a utilização de instrumentos validados capaz de avaliar o impacto da orientação tanto no processo de adesão dos pacientes aos necessários cuidados como na diminuição da ansiedade e insegurança do paciente e das complicações do procedimento. Mesmo assim, pode-se inferir, por meio das informações coletadas, que a orientação adequada minimizaria o desconhecimento dos pacientes acerca do exame coronariografia.

\section{REFERÊNCIAS}

1. Garcia DP, Arie S, Gama MN. Cinecoronariografia. In: Ghorayeb N, Meneguelo RS. Métodos diagnósticos em cardiologia. São Paulo: Atheneu; 1997. p.226-39.

2. Cunha AIG, Santos J FV et al. A enfermagem na cardiologia invasiva. São Paulo: Atheneu; 2006. p. 28-39.

3. Lange RA. Cateterismo cardíaco e avaliação hemodinâmica. In: Topol EJ. Tratado de cardiologia. 2a ed. São Paulo: Guanabara Koogan; 2005. p.1421-31.

4. Pontes $A C$, Leitão MTA, Ramos IC. Comunicação terapêutica em enfermagem: instrumento essencial do cuidado. Rev Bras Enferm. 2008 maio-jun; 61(3):312-8.

5. Carvalho DS, Christóforo BEB. Cuidados de enfermagem realizados ao paciente cirúrgico no período pré-operatório. Rev Esc Enferm USP. 2009 set-out; 1(43):14-22.

6. Minayo MCS. O desafio do conhecimento: pesquisa qualitativa em saúde. 8a ed. São Paulo: Hucitec; 2004.

7. Kruse MHL, Almeida MA, Keretzky KB, Rodrigues ESFP, Schenini FS, Garcia VM. Orientação pré-operatória da enfermeira: lembranças de pacientes. Rev Eletr Enf [periódico na Internet]. 2009 jun-jul [acesso em 18 jun. 2010]; 11(3): 494-500. Disponível em: http:// www. fen.ufg.br/ revista/v11/n3/v11n3a05.htm.

8. Logemann T, Luetmer P, Kaliebe J, Olson K, Murdock DK. Two versus six hour of bed rest following left-sided cardiac catheterization and a meta-analysis of early ambulation trials. Am J Cardiol. 1999; 84(4):486-8, A10.

9. Koch KT, Piek JJ, Winter RJ, Mulder K, Schotborgh CE, Tijssen J G, et al. Two hour ambulation after coronary angioplasty and stenting with $6 \mathrm{~F}$ guiding catheters and low dose heparin. Heart. 1999;81(1):53-6. 


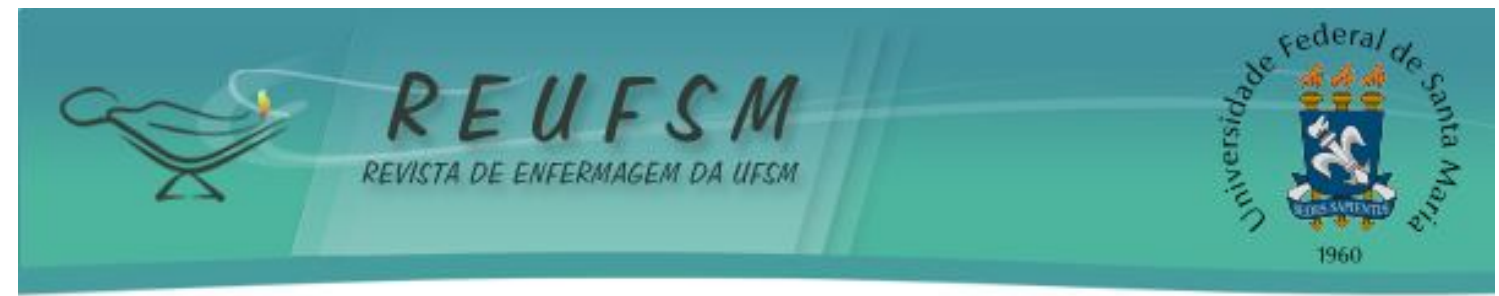

10. Rabelo ER, Morais MA, Aliti G, Rocha VS. Repouso de três horas não aumenta complicações após cateterismo cardíaco com introdutor arterial 6F:Ensaio Randomizado. Rev Bras Cardiol Invas. 2009 set-out; 17 (4):512-7.

11. Goldim JR. Manual de iniciação à pesquisa em saúde. 2a ed. Porto Alegre: Dacasa ; 2000.

12. Silva WV, Nakata S. Comunicação: uma necessidade percebida no período préoperatório de pacientes cirúrgicos. Rev Bras Enferm. 2005 nov-dez; 58(6): p.65-69.

13. Grazziano ES, Bianchi ERF. Nível de ansiedade de clientes submetidos a cineangiocoronariografia e de seus acompanhantes. Rev Latino Am Enfermagem. 2004 março; 12(2): p.168-74.

14. Freitas MC, Oliveira MF. Assistência de enfermagem a idosos que realizam cateterismo cardíaco: uma proposta a partir do modelo de adaptação de Calista Roy. Rev Bras Enferm. 2006 set-out; 59(5): p. 112-119.

15. Echer IC. Elaboração de manuais de orientação para o cuidado em saúde. Rev Latino Am Enfermagem. 2005 set-out; 13(4): 754-7.

Data de recebimento: 13/01/2011

Data de aceite: 29/03/2011

Contato com autor responsável: Christian Menuci

Endereço: Centro de Ciências da Saúde UNISINOS. Avenida Unisinos, 950 Bairro Cristo Rei CEP 93.022-000 - São Leopoldo - RS

E-mail: christian.menuci@gmail.com 